\title{
Improve Attendance Car Service Use Application
}

\author{
Joseph Kevin Wijaya \\ Faculty of Science Communication \\ Department of Information Systems \\ Tambora street 18E, Semarang
}

\begin{abstract}
This application makes people can use it easily to obtain satisfactory service and best. Therefore we have ideas to add the latest features that have never been in the service of other service applications. The higher the technological growth, we believe we've created an application that will evolve in the future of
\end{abstract}

Keywords - application, service, features, technology, growth of technology

\section{INTRODUCTION}

Nowadays, the technology is very advanced. People should follow the technology and think ahead because without technology they will find some difficulties. The present technology has an effect on the country itself, so if the country lives without technology, it is called undeveloped country. When we look backward, World War II, only developed countries such as America, Japan, Germany, and other European countries are able to make weapons, ships, planes and communication equipment. These days, there are many developed countries such as India, China, Korea and our own country, Indonesia, because of their technologies which help their growth rapidly.

Why technology is always influential for our country? Because people have been rely on the technology. Without technology they cannot communicate with others, especially those who are far one to another.
By the technology existence, people can communicate with others around the world without seeing each other or waiting the letters sent. They can use "webcam" to see their parents or relatives who live in other country. Those are the special effects of technology, it helps people to connect with others around the world of.

Technology will always develop, so we have an idea to make an application which makes people get satisfied and best service.

\section{II . LITERATURE REVIEW} customers

Ways to improve services for

1. The application can be used to administer many kinds of operations such as front to backend including: managing customer data , supplier data , work orders , sales transactions, the estimated cost, service, steam washing service, car's variety service,, service pricing based on the car category, history of customer , purchase, purchase returns, inventory , payable accounts, receivable account, stock data , member discounts, cash -in cash out transactions, and reports .

2. To improve the application by adding new features that are different from public service applications. Therefore, these applications will have new features. 
3. One of the features is instant messaging services without any charge and it is not necessary to ask other's phone number or BBM code. We believe this service will be beneficial for customers.

Instant messaging service features may be very simple because there are many similar services in the Google Play Store or APPS store. However, through this application, we are inspired to present this feature. Here are the steps you have to do:

- First you download the application

- Second, you simply input the plate number, the name of the vehicle's license, your name, and Email

- Third, verify your email address to get a password from us.

- Fourth enter your password in the application

And you are directly connected to our servers, and we also know what vehicle you are using. Meanwhile, if you have more than one types you do not need to to enter the name on vehicle license, this application will know and give you the option. if the name in vehicle licence is different, you can simply add by clicking "Other Car" and input the Name in the vehicle license or the plate number. The feature of instant messaging service will run, you just click the "Chat" and you are already connected to the "Service Advisor" online.

Booking Service feature of our application will allow users of a certain brand of car. We present these features as we know that the number of cars has increased and the car service will also be very crowded. The current distributor or car dealers have already used the telephone booking service. Using the Service Booking feature in our applications, customers do not have to spend any money because to run the application, you just need the "WIFI" or or internet connection. You can also try the
"PickUp Car"feature when you, the car owner cannot drivr the car to the service station. In addition to the features above, this application also have a variety of new features, namely:

1. Reminder

2. Details of total service

3. Car Status

Reminder is a feature that can warn you when it is time for service and if it is done the service center will notify you with a notification pop up on the screen of your smart phone

Details Total Service is a feature that directly informs you the service that has been done and the cost so that you can prepare the money before you take it from the service center.

Car status feature is highly favored because this feature provides complete current information on services that is being done. By clicking "car status", you will be able to see the condition of your car in the service center and what spare parts need to be replaced / repaired and the estimated time. If there are complaints or questions, you can do it through the "Chat" or Instant Messaging. That's the advantages of our application and we also have important features in our service application

Other feautures:

a. Features in Data Form:

- Item code

- Selling price

- Name of goods

- Stock

- Date of Stock

- Weekly Stock

- Selling price

b. Features in Purchase Transaction Form -

- No of bill.

- Item code

- Total

- Date

- Name of goods

- Discount

- Due date

- Stock Items 
- Grand Total

- How to Pay

- Purchase price

- Suppliers

- The total number of goods

- Total Debt

- Name

- Back

c. Features in Sales Transaction Form :

- No of the bill

- Item code

- Total

- Date

- Name of goods

- Discount

- Due date

- Stock Items

- Grand Total

- How to Pay

- Selling price

- Customer

- The total number of goods

- Total Debt

- Name

- Back

d. Features in Purchase Return Form

- Search Data

- Amount

- No Evidence

- Total Returns

- Supplier

- Selling price

- Goods

e. Features in Return of Sales Form

- Search Data

- Amount

- No Evidence

- Total Returns

- Customer

- Selling price

- Goods

f. Features in Repayment Form :

- Search Data

- Total Debt

- No Evidence

- Suppliers
- Remaining debt

\section{RESEARCH METHODOLOGY}

We conduct the interview because it is more effective, informative and we can listen directly from the users of the application. We can ask directly to the user what features should be added to improve customers' satisfaction levels, whether customers who use the car service application feel it ismore practical than before. On the other hand we also observe to get the data such as the number of people who have cars download this application that has been shared in Google App Store and Apple Store. We also conduct the reserach and get data from IDC of the market share of smart phones in that is used in Android, iOS, Blackberry, and Windows operating system because we are concerned with the applications we want to make and to focus on a particular operating system.

\section{RESULTS AND DISCUSSION}

1. How can we serve customers well? By understanding the customers' needs and providing solutions

2. What is needed by the customers when they have their cars serviced? Service quality, punctuality and spare part availability

3. Do you need car service applications? It Is needed to help customers knowing everything related to the services

4. Is current car service application useful for you? Features available cannot fulfill the customers' need and demand

5. How effective are the current car service applications? The current car service application only provide information on the specifications of the spare part but not on information of price, and availability of spare parts.

What features do you need in the application? (1) online consultation 
service; (2) catalog (consisting of specifications of units, the unit price of spare parts, and the estimated total cost of service and the time needed; (3) Customers' feedback (in the form Q \& A);

(4) Tracking system to know the progress / development and updates on services.

6 . What is required when the application is running? The ability of service advisors in answering questions and problems of customers through online

7. What do you expect if the application is running? It can provide answers or direct (time based) overview and estimation of the cost for all services

8. What do you think if spare parts can be ordered through online? We agree as it can increase the effectiveness of the company and on the customer side

9. What are the positive and negative impacts of the application on the customers? The negative impact is that the customers do not know about automotive and the positive impact is that the application can be used to educate the customers who do not know the automotive world.

10. Can the application increase the index of satisfaction? Yes, from customers' feedback, the companies can determine the performance, satisfaction and drawback and can make improvement.

11. Do you strongly support if there is a car service application? Strongly support

12. Do you think that a chat feature with Service Advisor is very useful? Right. these features can answer all customers' needs and to start consultancy.

13. What can of screen view do you want? Simple and easy User experience and user interface so that customers can understand the application.

14. Are you happy to wait in the garage while you have your car serviced? We were not happy at all if we had to wait while our car is repaired because it will take a lot of our time and mess up our schedule.

15. Do you need information about the estimated service cost of your car? This is a feature that is appropriate for consumers because it will be easier for customers when they are busy and do not have time to ask about costs.

16. Does this application need to display information on the availability of spare parts required for your car? We think if the application displays information on the availability of parts needed. We will be satisfied because we can check first if not we will feel dissatified.

17. If the application display the information on progress of the service work, does it helps you to organize your schedule? Very helpful because we are people who work with high mobility and if our car is serviced, our job will be chaotic.

18. Should the apllication be able to be used for one particular brand or other brands of cars you have today? We better use one application for one brand because it relates to our privacy if an application can be used for more than one brands, that mean other brands will know what cars we have.

19. If you have to go to the garage or service center, do you do it yourself or get someone to do it or get the garage to take your car? It depends on the person himself, if he is busy, he will ask the garage to take it.

20. Will it be helpful if you are reminded by an application that it is time to have your car serviced? This feature will be very helpful because sometimes customers do not care and think it is just a simple thing to do the maintance regularly while it can cause a fatal result Therefore, we agree that there is a warning so that the user can become more aware or care about the maintance schedulle. 
Display Applications

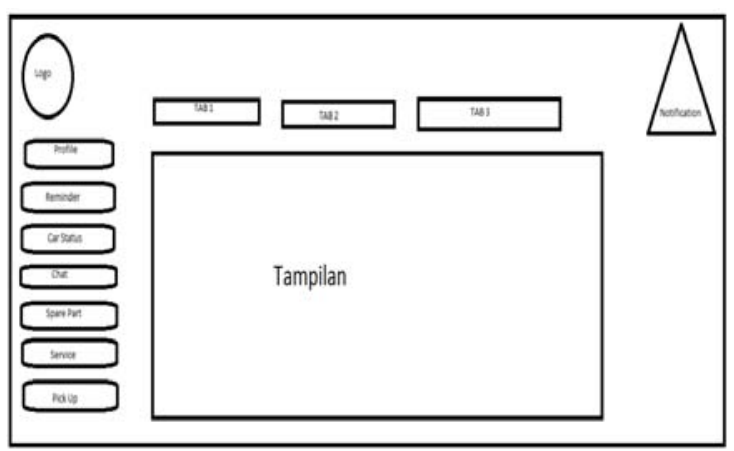

We present the features tab as shown above because we think that feature would be needed and helpful for customers to have used the application. This function is like in the browser.

\section{Conclusions}

We conclude that people are interested in car service because in the future we believe that application relating to a car service will grow. We assess that today people rely on their smartphone and it has become primary need. Based on the IDC, the most widely used Operating System is based on Android and iOS. We will focus on two Operating Systems. However, we will also use other operating system that has smaller market share because we will follow the development of technology. In 2010-2012 it was based on the Blackberry Operating System and in 2013 to present operating system based on Android and iOS dominate the World. Indonesia still needs applications of this kind and the current Indonesian government has started to improve broadband in Indonesia to maximize the technology to keep up with other countries

\section{REFERENCES}

[1] http://www.softwarebengkel.com/ [2] http://www.sistemsmart.com/software bengkel/

[3]http://kopipagi.info/index.php/2014/08/ 31/aplikasi-teknologi-buat-kinerjabengkel-makin-efisien/

[4]http://www.idc.com/prodserv/smartpho ne-market-share.jsp

[5] http://eprints.uad.ac.id/1882/2/SI_Akuta nsi_pada_Bengkel.pdf 